\title{
Estimating the electric field response to the Halloween 2003 and September 2017 magnetic storms across Scotland using observed geomagnetic fields, magnetotelluric impedances and perturbation tensors
}

\author{
Fiona Simpson ${ }^{1, *}$ and Karsten Bahr ${ }^{2}$ \\ ${ }^{1}$ School of Ocean and Earth Science, University of Southampton, National Oceanography Centre, European Way, \\ SO14 3ZH Southampton, UK \\ ${ }^{2}$ Institut für Geophysik, Georg-August Universität Göttingen, Friedrich-Hund-Platz 1, 37073 Göttingen, Germany
}

Received 25 March 2020 / Accepted 31 August 2020

\begin{abstract}
Geomagnetic storms generate heightened magnetovariational activity, which induces electric fields that drive hazardous currents known as geomagnetically induced currents (GICs) through manmade technological conductors including power transmission lines, railway networks and gas pipelines. We multiply magnetotelluric (MT) impedances from 23 sites in Scotland and northern England with measured geomagnetic field spectra from the Halloween 2003 and September 2017 storms to estimate maximum peak-to-peak, electric field magnitudes and directions for these storms, which we present as hazard maps. By sampling these electric fields in the direction of the longest $(>50 \mathrm{~km})$, high-voltage $(275$ and $400 \mathrm{kV}$ ) Scottish power transmission lines and integrating along their lengths, we estimate their associated transmission-line voltages. Lateral electrical conductivity variations in the Earth generate horizontal magnetic field gradients. We investigate the effect of these gradients on electric field estimates obtained using remote magnetic fields by applying a correction to the impedance tensor derived from the magnetic perturbation tensor between the local MT site and the remote magnetic field site. For the September 2017 storm, we also compare our estimated electric fields with a unique dataset comprising measured storm-time electric fields from 7 MT sites. We find that peak-to-peak, electric field magnitudes may have reached $13 \mathrm{~V} / \mathrm{km}$ during the Halloween storm in some areas of the Scottish Highlands, with line-averaged electric fields $>5 \mathrm{~V} / \mathrm{km}$ sustained along a number of long-distance, high-voltage power transmission lines; lineaveraged electric fields for the September 2017 storm are $1 \mathrm{~V} / \mathrm{km}$ or less. Our surface electric fields show significant site-to-site variability that arises due to Earth's internal 3D electrical conductivity structure, as characterised by the MT impedance tensors.
\end{abstract}

Keywords: magnetic storms / eelectric fields / magnetotellurics / hazard maps / geomagnetically induced currents

\section{Introduction}

A bit like Jekyll and Hyde (Stevenson, 1886), the Sun exerts both benign and malevolent influences on our society, providing nurturing warmth and light on the one hand and cancer-causing UV rays and magnetic disturbances that threaten our technological infrastructure (e.g., Boteler, 2003; Cannon et al., 2013) on the other. Large magnetic storms are observed on Earth following coronal mass ejections (CME), which expel highvelocity charged particles (called plasma) that carry strong magnetic flux, increasing solar-wind pressure and magnetic field intensity and driving rapidly-varying electric currents in Earth's

\footnotetext{
*Corresponding author: f. simpson@soton. ac.uk
}

ionosphere (Chapman \& Ferraro, 1931). These external electromagnetic source fields induce electric fields in the Earth, the magnitudes and polarisations of which depend on Earth's internal, multi-dimensional electrical conductivity structure (e.g., Simpson \& Bahr, 2005). These induced electric fields, in turn, give rise to quasi-dc currents known as "geomagnetically induced currents" (GICs) in man-made technological conductors (e.g., Kelbert, 2019 and references therein). GICs induced during the largest magnetic storm on record - the Carrington event of 1859 (Hodgson, 1859; Carrington, 1860; Tsurutani et al., 2003; Cliver \& Svalgaard, 2004) - caused widespread disruption of the telegraph communication network. Subsequent large magnetic storms in March 1989 and around Halloween 2003 tripped relays leading to large-scale, 
economically-damaging power outages in Québec, Canada (Boteler, 1994; Bolduc, 2002) and Malmö, Sweden (Pulkkinen et al., 2005), respectively.

In the UK, our embracement of green energy in the form of offshore windfarms is arguably exposing our power networks to greater risks from magnetic storms, since induced voltages are directly proportional to the distances over which induced electric fields are integrated and our dependence on long-distance, high-voltage, power transmission lines is increasing (OECD, 2018). Railways and gas pipelines also form conductive networks that are affected by geomagnetic storms (Gummow \& Eng, 2002; Viljanen et al., 2006; Krausmann et al., 2015).

Similar to the fluctuations in the prices of stocks and shares traded on the stock market, extreme fluctuations in magnetic field intensity are governed by non-stationary processes. Therefore, our knowledge concerning the maximum-likely intensity of a future extreme magnetic event is limited. The Halloween 2003 (28th-31st October 2003) magnetic storm was registered as an extreme space weather event in Scotland, with GICs of 42 A recorded in the Scottish power grid at Strathaven, which have been associated with localised, surface electric fields of up to $5 \mathrm{~V} / \mathrm{km}$ based on $3 \mathrm{D}$ thin-sheet modelling (Thomson et al., 2005).

Time derivatives of horizontally-polarised, storm-time magnetic fields $(\partial B / \mathrm{d} t)$ are sometimes used as proxies for electric fields that drive GICs (e.g., Pulkkinen et al., 2006). However, differences in scaling factors between in-situ measurements of $\partial B / \mathrm{d} t$ and electric fields at 7 sites $(\mathrm{ACH}, \mathrm{ELC}, \mathrm{CAI}, \mathrm{LEA}$, RAN, MAR, TAN, Fig. 1) during the September 2017 storm (Simpson \& Bahr, 2020a) have demonstrated that $\partial B / \mathrm{d} t$ is no substitute for in-situ measurements of the electric field that better constrain local, multi-dimensional heterogeneity of the subsurface electrical conductivity structure. This multidimensionality can be described by bi-variate transfer functions (impedance tensors and perturbation tensors) between simultaneously recorded electric and magnetic fields (e.g., Simpson \& Bahr, 2005) that can be considered stationary in stable tectonic environments (e.g., Hanekop \& Simpson, 2006). Sources of three-dimensionality and strongly-polarised twodimensionality in Scotland and northern England include (i) the coastline, which presents a transition between resistive rock $(>1000 \Omega \mathrm{m})$ and conductive seawater $(0.25 \Omega \mathrm{m})$; (ii) near-surface resistive $(>1000 \Omega \mathrm{m})$ granite batholiths flanked by conductive $(<100 \Omega \mathrm{m})$ sedimentary basins (Simpson \& Warner, 1998); (iii) major NW-SE trending fault systems (Fig. 1) - including the Great Glen Fault (Kennedy, 1946), Highland Boundary Fault (Tanner, 2008) and Southern Uplands Fault (Oliver et al., 2002) - associated with plate collision and closure of the Iapetus Ocean during the Caledonian orogeny; (iv) NE-SW trending mountain ranges also related to the Caledonian orogeny and (v) a zone of mid-crustal conductivity (Hutton et al., 1977; Simpson \& Warner, 1998) that is a common feature of stable tectonic regions (Simpson, 1999). Electrical conductivities are known to vary by several orders of magnitude across tectonic boundaries of the type present in Scotland, due for example to saline fluids, graphite and other minerals in fault zones (e.g., Simpson, 2000), with space weather studies conducted in the US demonstrating their firstorder importance in influencing the electric fields that drive GICs (e.g., Lucas et al., 2020). Further, although estimation of transmission-line voltages involves integration and, therefore averaging, of electric fields, significant variability associated with 3D Earth conductivities can be expected to persist in electrically complex environments compared to the $1 \mathrm{D}$ case (e.g., Lucas et al., 2018).

To date, only ocean bathymetry and near-surface $(<5 \mathrm{~km})$ conductivity variations have been extensively considered in studies of the hazards associated with magnetic storms in the UK (e.g., Beamish et al., 2002; Ivannikova et al., 2018). When, as in these models, a near surface model of ocean bathymetry is underlain by unrealistically high $1 \mathrm{D}$ electrical resistivities, the coast effect is artificially amplified. Simpson \& Bahr (2020a) have used 3D modelling (Siripunvaraporn et al., 2005) to demonstrate that the coast effect is minimal for long-period magnetotelluric (MT) sites in central Scotland, whereas the electrical resistivity of the underlying deep crust and mantle exerts a first-order influence on the induced electric fields.

Here, we use impedance and perturbation tensors derived from long-period MT array data (Fig. 1) collected by the authors between 2017 and 2018 and geomagnetic observatory data from a time-period spanning the Halloween 2003 magnetic storm to generate hazard maps for Scotland. These impedance and perturbation tensors characterise the Earth's 3D electrical conductivity structure and allow its effects on storm-time electric fields to be investigated. We consider the effect of the stormtime magnetic source fields on our results by extending our analysis to the September 2017 storm, which we recorded at 7 of our MT sites (Simpson \& Bahr, 2020a, 2020b).

\section{Methods}

\subsection{Electric fields}

We multiplied MT impedance and magnetic perturbation tensors derived from 23 MT sites (Fig. 1) in Scotland and northern England with magnetic field spectra derived from time series measured at ESK geomagnetic observatory to model the electric fields associated with the Halloween 2003 magnetic storm in this region. The impedance tensors, $Z_{i j}$, were processed (e.g., Egbert \& Booker, 1986; Simpson \& Bahr, 2005) from discrete windows of electromagnetic time series recorded over several months between 2017 and 2018 according to the standard, plane-wave formulation (e.g., Simpson \& Bahr, 2005):

$$
\left(\begin{array}{l}
E_{x}(\omega) \\
E_{y}(\omega)
\end{array}\right)=\left(\begin{array}{ll}
Z_{x x}(\omega) & Z_{x y}(\omega) \\
Z_{y x}(\omega) & Z_{y y}(\omega)
\end{array}\right)\left(\begin{array}{l}
B_{x}(\omega) \mu_{0} \\
B_{y}(\omega) \mu_{0}
\end{array}\right)
$$

where $\boldsymbol{E}$ denotes electric field, $\boldsymbol{B}$ denotes magnetic field, $\omega$ is angular frequency and subscripts " $x$ " and " $y$ " denote northsouth and east-west polarised fields, respectively. Long-term stability of the electric fields used to compute the MT impedances was ensured by using non-polarisable silver-silver chloride electrodes (Filloux, 1987; Simpson \& Bahr, 2005) buried to depths $>50 \mathrm{~cm}$. Magnetic fields were measured using low-noise (Magson/Bartington) fluxgate magnetometers. Recording durations were 3 months or more at all sites. The long recording durations coupled with remote site locations ensured high-quality impedance tensors in the period range $10-30,000 \mathrm{~s}$, with errors in the impedance tensor components of less than $1 \%$ for periods up to $1000 \mathrm{~s}$ and less than $3 \%$ at longer periods. The diffusive nature of electromagnetic fields means that the $2 \times 2$ impedance tensor obtained for each 


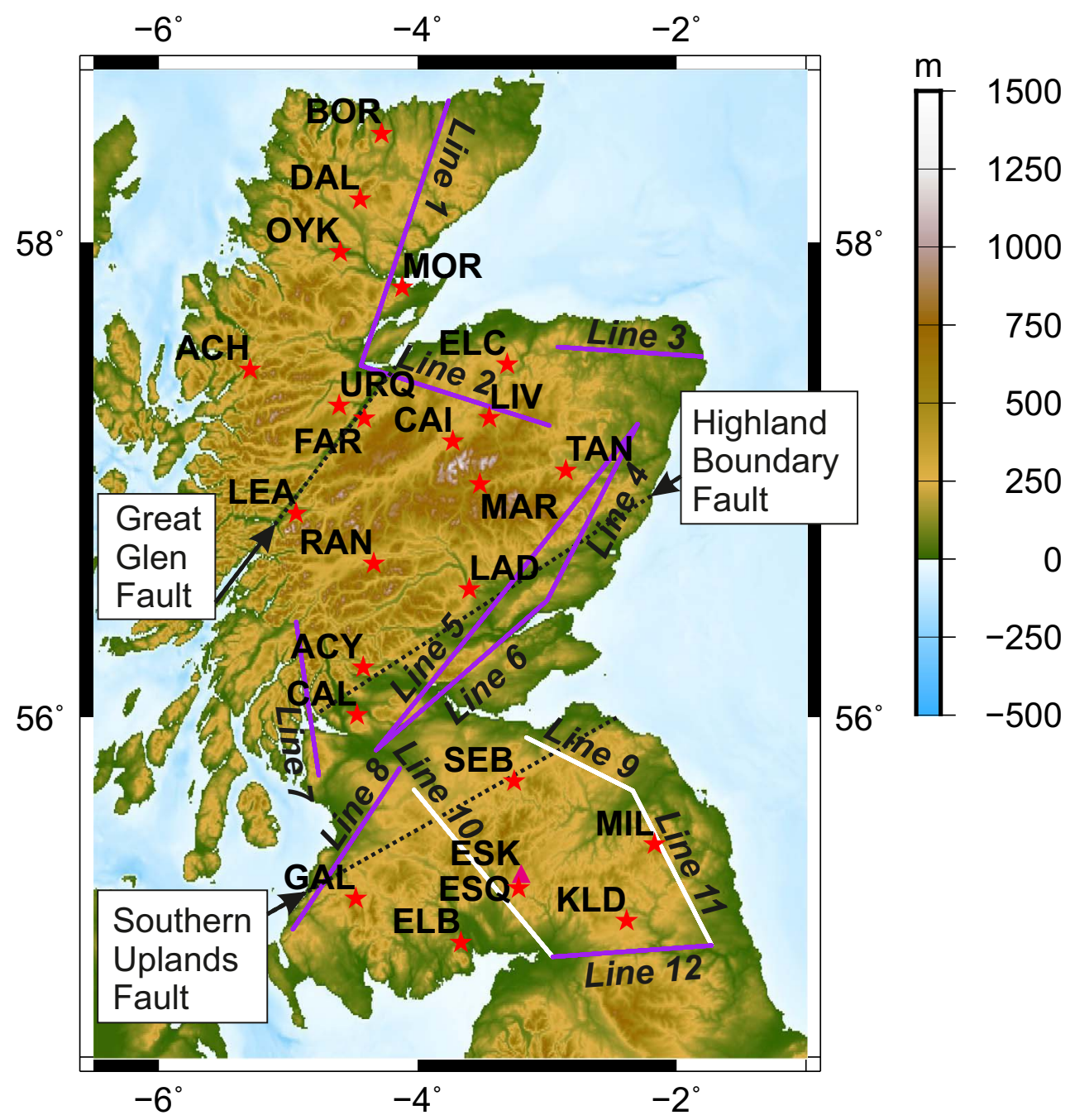

Fig. 1. Locations (red stars) and names of 23 MT sites installed in Scotland and northern England during 2017 and 2018 . Pink triangle marks the position of ESK geomagnetic observatory. Purple and white lines are the longest $(>50 \mathrm{~km}) 12$ high-voltage $-275 \mathrm{kV}$ and $400 \mathrm{kV}$, respectively - transmission lines in the region (Viljanen et al., 2013; Kelly et al., 2017). Dashed lines delineate the Great Glen Fault (Kennedy, 1946), Highland Boundary Fault (Tanner, 2008) and Southern Uplands Fault (Oliver et al., 2002). The highest topography is located between sites CAI and MAR. This region is referred to as the Cairngorms.

sounding period characterises a volume of Earth, whose size depends on the frequency of the transfer function and the electrical conductivities sampled. Therefore, instruments do not need to be placed in the direct vicinity of electromagnetically noisy, high-voltage power lines in order to sample the deep Earth below them.

Multi-dimensional electrical conductivity anomalies also give rise to horizontal magnetic gradients, which can be quantified in terms of the horizontal magnetic perturbation tensor $\boldsymbol{W}_{i j}$ (Schmucker, 1973; Simpson \& Bahr, 2005):

$$
\left(\begin{array}{l}
B_{L x}(\omega) \\
B_{L y}(\omega)
\end{array}\right)-\left(\begin{array}{l}
B_{O x}(\omega) \\
B_{O y}(\omega)
\end{array}\right)=\left(\begin{array}{ll}
w_{x x}(\omega) & w_{x y}(\omega) \\
w_{y x}(\omega) & w_{y y}(\omega)
\end{array}\right)\left(\begin{array}{l}
B_{O x}(\omega) \\
B_{O y}(\omega)
\end{array}\right)
$$

where subscripts " $L$ " and " $O$ " denote fields measured at a local measurement site and a simultaneously-recording reference or observatory site, respectively.
Studies involving $\boldsymbol{W}_{i j}$ are often referred to as "geomagnetic depth sounding" (GDS). In regions with significant horizontal magnetic gradients, errors may arise if magnetic fields from regional magnetic observatories are used to estimate local, storm-time electric fields. However, knowing $\boldsymbol{W}_{i j}$ from GDS, horizontal magnetic gradients can be corrected for by multiplying the measured MT impedances by a correction factor that is derived from equations (1) and (2). From equation (2), we have:

$$
\boldsymbol{B}_{L}=\boldsymbol{W} \boldsymbol{B}_{O}+\boldsymbol{B}_{O}=(\boldsymbol{W}+\mathbf{1}) \boldsymbol{B}_{O} .
$$

From equation (1), we have:

$$
\boldsymbol{E}_{L}=\boldsymbol{Z}_{L} \boldsymbol{B}_{L} / \mu_{0} .
$$

Combining equations (3) and (4) yields:

$$
\boldsymbol{E}_{L}=\boldsymbol{Z}_{L}(\boldsymbol{W}+\mathbf{1}) \boldsymbol{B}_{O} / \mu_{0} .
$$



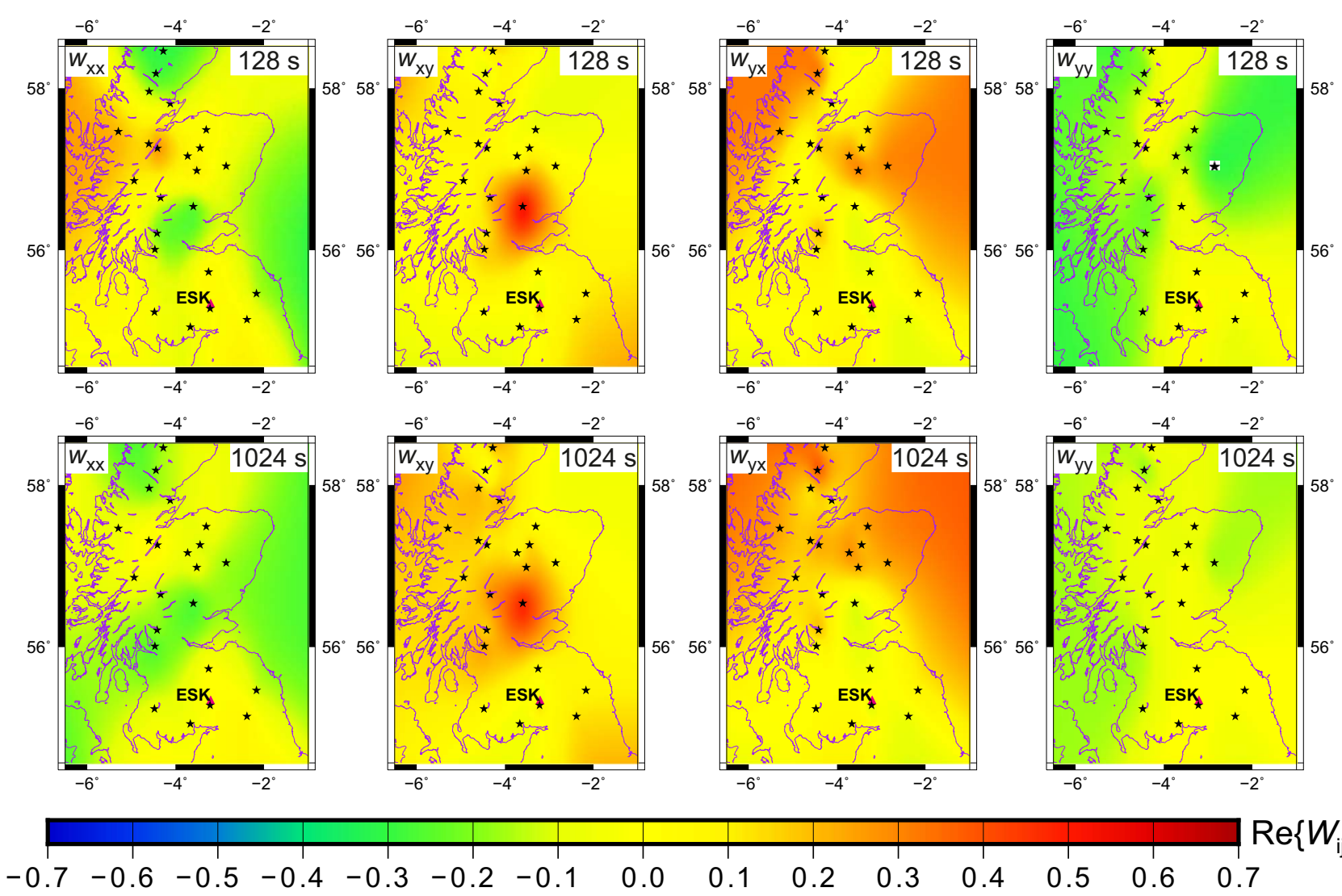

0.6

0.7

Fig. 2. Horizontal real components of the perturbation tensor, $\boldsymbol{W}_{i j}$, at periods of $128 \mathrm{~s}$ and $1024 \mathrm{~s}$ interpolated using bicubic splines (Smith \& Wessel, 1990). Stars indicate MT measurement sites.

Therefore, the correction factor that is required by the substitution of the observatory magnetic field for the locally measured magnetic field is $\boldsymbol{W}_{i j}+\mathbf{1}$ (Simpson \& Bahr, 2020a). We will refer to impedances to which this correction factor has been applied as "modified impedances", $\boldsymbol{Z}_{i j}^{\prime}$.

During magnetic storms, electromagnetic source fields deviate from plane waves, which could be a source of error for our technique. However, we have validated our technique against data recorded at 7 sites in Scotland during the September 2017 magnetic storm (Simpson \& Bahr, 2020b) and shown that we were able to acceptably recover the observed electric fields from measured magnetic fields, impedance and perturbation tensors (Simpson \& Bahr, 2020a). Frequency-domain multiplication or convolution techniques (see, also Kelbert et al., 2017) of estimating electric fields require fewer assumptions, utilise more realistic source fields and are potentially more robust than modelling methods that rely on plane-wave or line currents to generate synthetic magnetic source fields combined with thin-sheet electrical conductivity models (e.g., Beamish et al., 2002). In the presence of strong, lateral, electrical conductivity gradients, the inclusion of our perturbation-tensor correction will further improve the accuracy of electric field estimates compared to interpolating geomagnetic observatory data over large regions without correcting for the use of a non-local magnetic source field.

The electric field spectra were Fourier transformed back to the time domain in order to determine the expected electric field time series at each site within the MT array before, during and after the Halloween 2003 storm. This enabled estimation of the maximum peak-to-peak electric fields in $\mathrm{V} / \mathrm{km}$ at different positions within the MT array. We use peak-to-peak electric field magnitudes rather than absolute magnitudes, because we are primarily interested in relative spatial differences and there is no consistent defined baseline for different sites and polarisations. Geoelectromagnetic fields have inherent DC offsets. The magnetic main field generates a DC offset of approximately $30,000 \mathrm{nT}$ compared to magnetovariational fluctuations of 0.1-50 nT. Meanwhile, the electric field offset is site- and polarisation-dependent and can be 10-50 times larger than the electric variational field - a phenomenon referred to as the "geobattery" (Bigalke \& Grabner, 1997). These DC shifts are either compensated for by applying a constant voltage during recording (see Simpson \& Bahr, 2005) to enable higher resolution of the variational field by a 16-bit A/D converter or fully sampled when a 24-bit A/D converter is used. From the latter case, we know that there is no spatial correlation between the DC offsets of the electric field at different sites. Therefore, maps of absolute electric field values would be dominated by the spatial variation of these DC offsets and joint consideration of different electric field polarisations to obtain electric-field components in any specific direction along transmission lines would be unviable. Further, estimation of MT impedance tensors involves Fourier transforming electromagnetic time series into the frequency domain. As the DC component represents a signal with a frequency of $0 \mathrm{~Hz}$, it cannot be retrieved following Fourier transform. So, electric fields computed from MT impedance tensors contain no information about the 

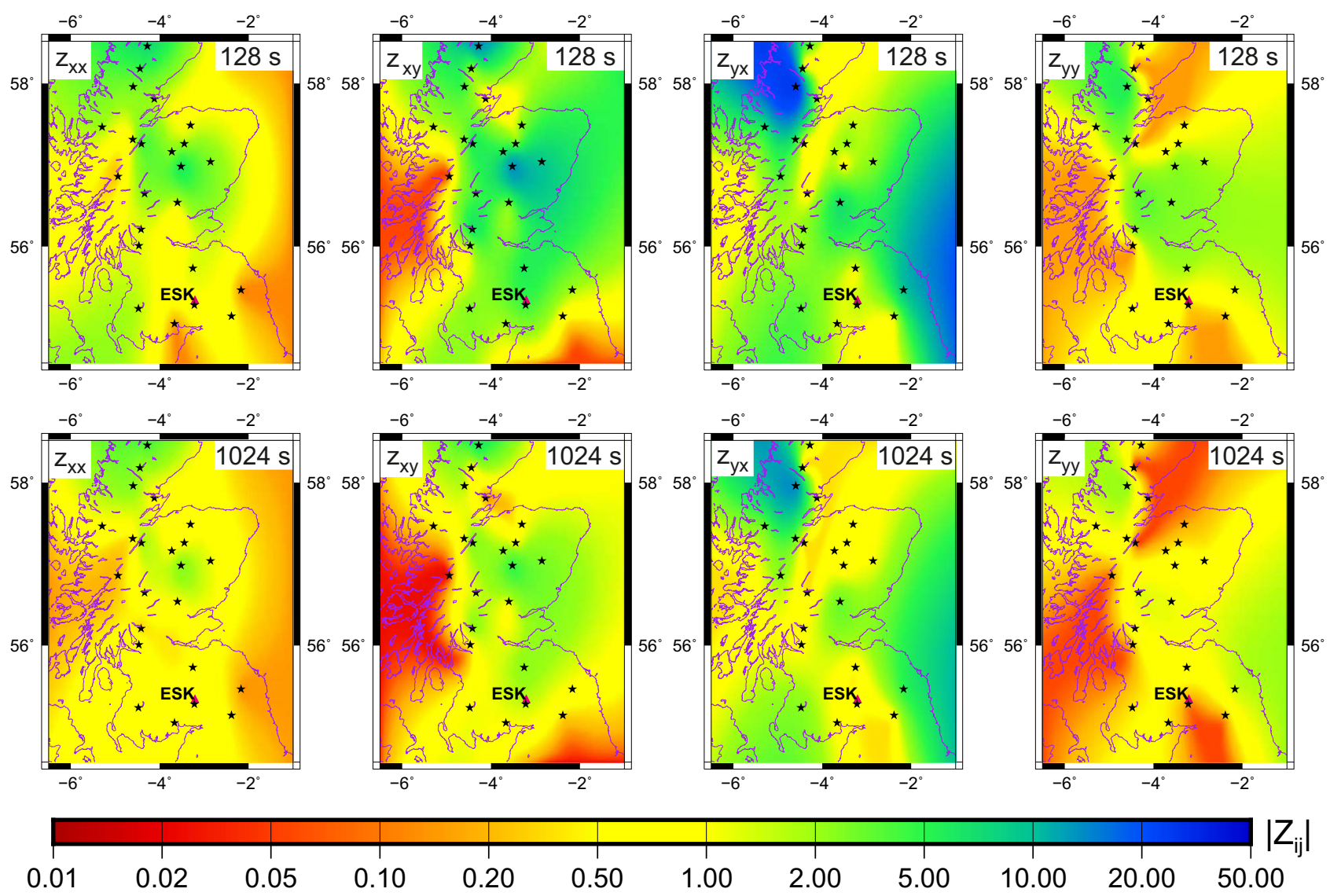

Fig. 3. Impedance tensor components, $\boldsymbol{Z}_{i j}$, at periods of $128 \mathrm{~s}$ and $1024 \mathrm{~s}$ interpolated using bicubic splines (Smith \& Wessel, 1990). Stars indicate site locations.

absolute baseline of the original fields from which they were computed - i.e., in reality, these fields do not fluctuate about zero, but rather about an unknown level that incorporates a DC shift. This phenomenon should not be confused with sitedependent static shifts of MT impedances (e.g., Simpson \& Bahr, 2005), which are caused by DC amplification of the amplitudes of electric field variations, rather than by DC shift of the baseline (Bigalke \& Grabner, 1997) about which they fluctuate. This DC offset of the baseline is a non-trivial problem for GIC modelling (in which the DC offset has been neglected) as it could affect the assumed polarity and absolute magnitudes of electric fields input to network models.

The external magnetic fields that induce electric fields within the Earth during different magnetic storms have different dominant frequency compositions and polarisations. Therefore, the form of the electric fields obtained through frequencydomain multiplication of storm-time magnetic field data with impedance tensors will differ for different storms. To investigate this effect, we performed a similar estimation of the maximum peak-to-peak electric field amplitudes for the September 2017 storm using storm-time magnetic data (Simpson \& Bahr, 2020b) measured at RAN (Fig. 1) during our MT fieldwork.

\subsection{Transmission-line voltages}

We model the coupling between the amplitudes and polarisations of storm-time electric fields and transmission-line geometry. The voltages arising in individual high-voltage transmission lines are obtained by integrating the surface electric fields in the direction of the individual line over its length. In practice, we interpolated the electric fields obtained at our MT sites using natural bicubic splines (Smith \& Wessel, 1990) and extracted north-south $\left(E_{x}\right)$ and east-west $\left(E_{y}\right)$ polarised values at $50 \mathrm{~m}$ intervals along 12 transmission lines with lengths exceeding $50 \mathrm{~km}$ (Fig. 1) to derive line-averaged $E_{x}$ and $E_{y}$ electric fields by summing and dividing by the number of values obtained. We then used simple trigonometry to calculate the mean-average field in the direction of each line and multiplied this by the length of the line to estimate the storm-related voltage through it. GICs at any point within an electric-power network depend on the line voltages within the entire network. This requires knowledge of grounding resistances and voltages and transmission-line resistances. This is an engineering problem with many assumptions required about power-system configuration and dynamics. Here, we confine ourselves to the geophysical aspects of the problem and calculate only line-average electric fields and transmission-line voltages, not GICs.

\section{Results}

\subsection{Horizontal magnetic gradients and MT impedances}

Horizontal magnetic gradients (perturbation tensors, $\boldsymbol{W}_{i j}$ ) for Scotland and northern England relative to ESK geomagnetic 

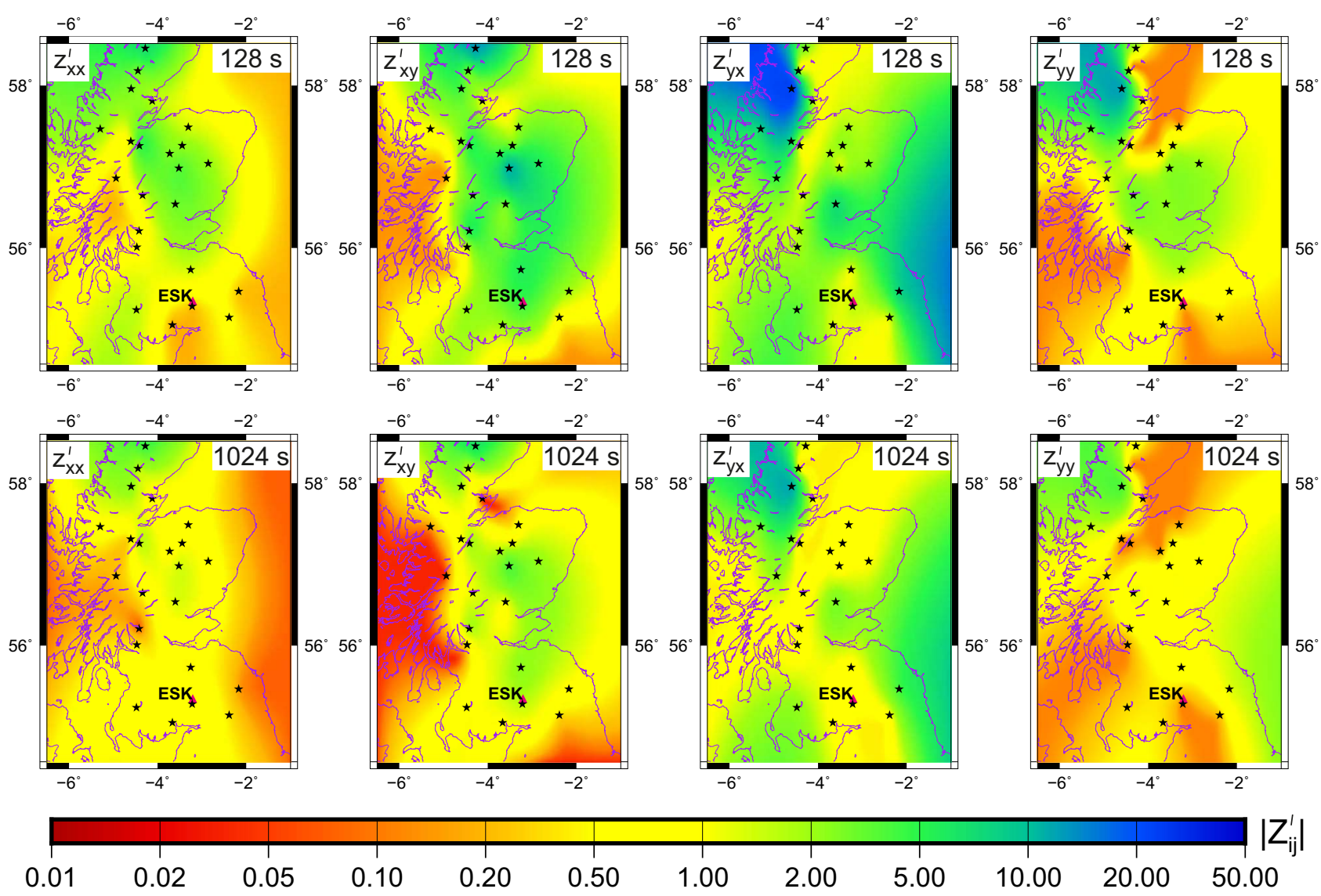

Fig. 4. Modified impedance tensor components, $\boldsymbol{Z}_{i j}^{\prime}$, following perturbation-tensor correction, at periods of $128 \mathrm{~s}$ and $1024 \mathrm{~s}$ interpolated using bicubic splines (Smith \& Wessel, 1990). Stars indicate site locations.

observatory are shown in Figure 2 for two representative sounding periods a decade apart. Regions contoured in yellow have negligible magnetic field gradients relative to ESK; regions contoured in green and orange indicate small negative or positive anomalies, respectively. The most prominent GDS anomaly occurs around site LAD (Fig. 1), where the horizontal magnetic field strength for the $w_{x y}$ component (Fig. 2) is approximately 1.5 times greater than at the reference station, ESK. Small anomalies are also evident in the environs of sites ACY and CAL (Fig. 1), which lie north of the city of Glasgow.

Maps of contoured impedances, $\boldsymbol{Z}_{i j}$, and modified impedances, $\boldsymbol{Z}_{i j}^{\prime}$, are presented in Figures 3 and 4, respectively, for the same two representative periods (128 s and $1024 \mathrm{~s})$ as the perturbation tensors, $\boldsymbol{W}_{i j}$, presented in Figure 2. There are small, but discernible differences between $\boldsymbol{Z}_{i j}$ and $\boldsymbol{Z}_{i j}^{\prime}$. These are investigated further in Figure 5, where we display the relative percentage differences between the off-diagonal moduli of $\boldsymbol{Z}_{i j}$ and $\boldsymbol{Z}_{i j}^{\prime}$ :

$$
\Delta \boldsymbol{Z}_{i j}=\frac{\left|\boldsymbol{Z}_{i j}\right|-\left|\boldsymbol{Z}_{i j}^{\prime}\right|}{\left|\boldsymbol{Z}_{i j}\right|} \times 100
$$

The largest relative differences are seen at LEA for north-south polarised electric fields $\left(\Delta Z_{x y}\right)$ and at RAN for east-west polarised fields $\left(\Delta Z_{y x}\right)$.

\subsection{Maximum electric field magnitudes during Halloween 2003 storm}

Maximum peak-to-peak electric fields associated with the Halloween 2003 magnetic storm occur at 21:20 UT on 30th October 2003 for both north-south and east-west polarisations. Their time series for 3 sites are shown in Figure 6. As the electric field time series shown in Figure 6 are derived by frequency-domain multiplication of the same, regional, magnetic field spectra with local impedances, site-to-site differences between these electric field time series can be attributed to differences in Earth's 3D conductivity structure, as embodied in the impedance tensors.

Maximum peak-to-peak electric fields vary by more than an order of magnitude (from $<1 \mathrm{~V} / \mathrm{km}$ to $>13 \mathrm{~V} / \mathrm{km}$ ) across Scotland and northern England (Fig. 7). Comparing Figures 7a and $7 \mathrm{c}$, and $7 \mathrm{~b}$ and $7 \mathrm{~d}$, some differences between the maximum peak-to-peak electric field magnitudes estimated from measured impedances $\left(\boldsymbol{Z}_{i j}\right)$ versus those estimated from modified impedances $\left(\boldsymbol{Z}_{i j}^{\prime}\right)$ are discernible, particularly in the south-western part of our array.

A low-risk corridor of small magnitude (dominantly contoured in blue with some green) electric fields runs from Moray/Aberdeenshire (sites MOR, ELC; Fig. 1) across to Argyll (sites LEA, RAN; Fig. 1) and down via Dumfries and Galloway (site ELB; Fig. 1) to northern England (site KLD; 
a)

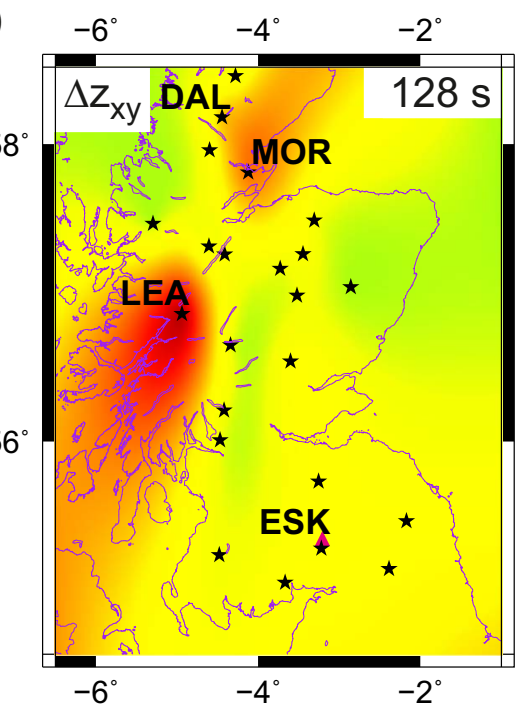

c)

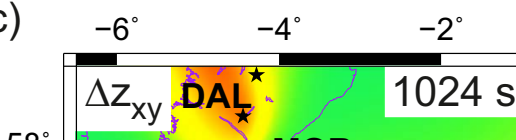

b)

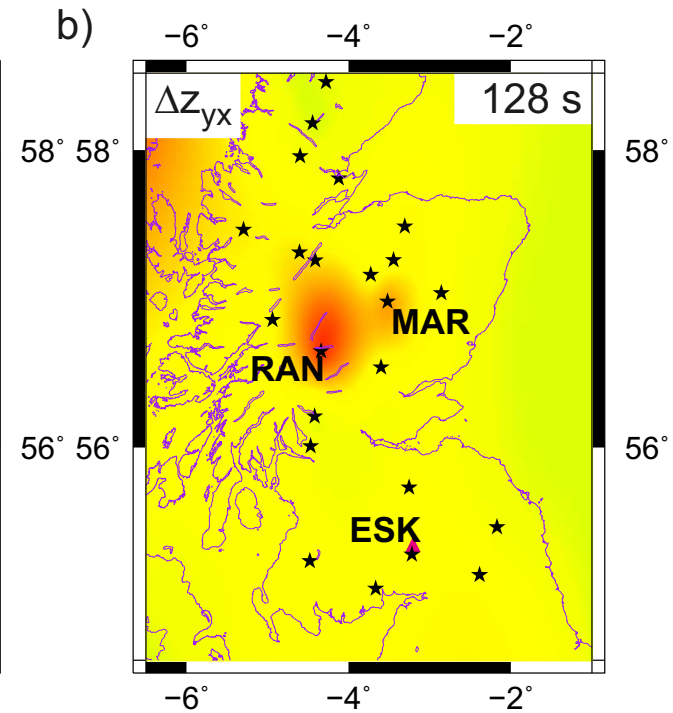

d)

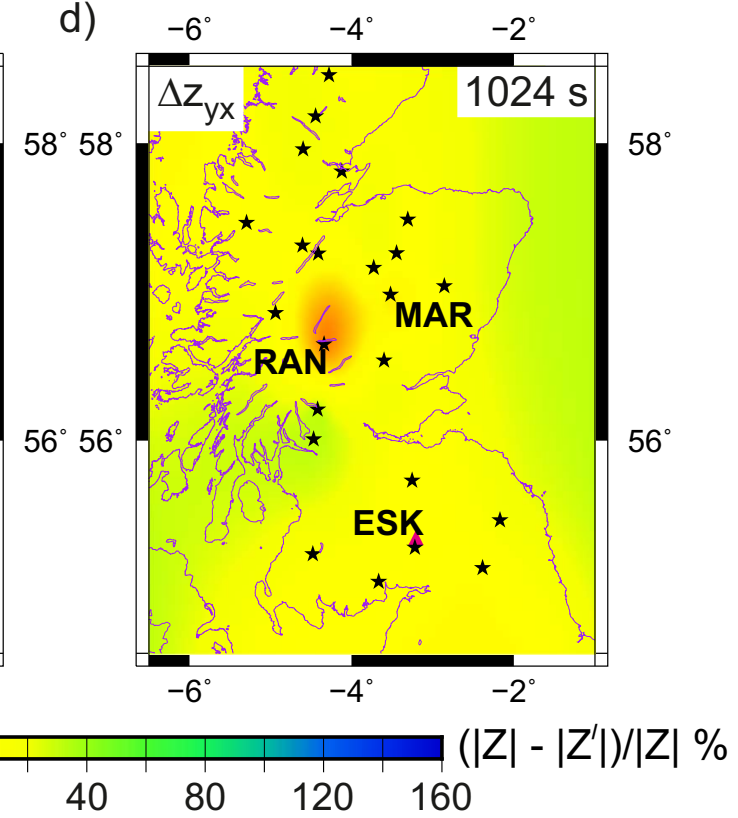

Fig. 5. Relative percentage differences: (a) $\Delta Z_{x y}$ and (b) $\Delta Z_{y x}$ at $128 \mathrm{~s}$; (c) $\Delta Z_{x y}$ and (d) $\Delta Z_{y x}$ at $1024 \mathrm{~s}$ interpolated using bicubic splines (Smith \& Wessel, 1990).

Fig. 1). Sites BOR, OYK and MAR (Fig. 1) represent areas of higher risk. This can be attributed to higher impedances in these regions (Figs. 3 and 4). In these regions, storm-time electric fields significantly exceed the $2 \mathrm{~V} / \mathrm{km}$ easterly polarised, storm-time, electric fields inferred (Boteler, 1994) to have caused a power outage in Québec, Canada during the March 1989 magnetic storm. The largest, localised peak-to-peak electric fields in Scotland during the Halloween magnetic storm (Fig. 7) are estimated to have reached $12-13 \mathrm{~V} / \mathrm{km}$ at MAR and BOR (Fig. 1). Significant differences are apparent between the $E_{x}$ fields estimated from $\boldsymbol{Z}_{i j}$ and $\boldsymbol{Z}_{i j}^{\prime}$, respectively, in the region through which high-voltage transmission-lines 7 and 8 run (Fig. 1).

Beggan et al. (2013) have previously presented $E_{x}$ and $E_{y}$ polarised electric fields for a storm 5 times as intense as the Halloween storm computed using a thin-sheet model
(BGS2012) of ocean bathymetry and near surface $(<4 \mathrm{~km})$ conductances assumed from surface geology underlain by a uniform $900-\Omega \mathrm{m}$ half-space to infinity. A $900-\Omega \mathrm{m}$ half-space is unrealistically resistive and homogeneous for the purpose of representing stable-tectonic, deep continental crust (e.g., Haak \& Hutton, 1986; Haak et al., 1997; Simpson \& Warner, 1998; Simpson, 1999), upper mantle (e.g., Kurtz et al., 1993; Simpson, 2001; Simpson, 2002) and the mid-mantle transition zone (e.g., Bahr et al., 1993; Simpson, 2002). Our hazard maps (Fig. 7) show much more spatial variability than those obtained from BGS2012, demonstrating that full characterisation of the electrical conductivity structure of the deep crust and mantle below the UK is a prerequisite for accurate estimation of storm-time electric fields.

The maximum peak-to-peak $E_{x}$ and $E_{y}$ magnitudes shown in Figure 7 occur concurrently. Therefore, the information from 

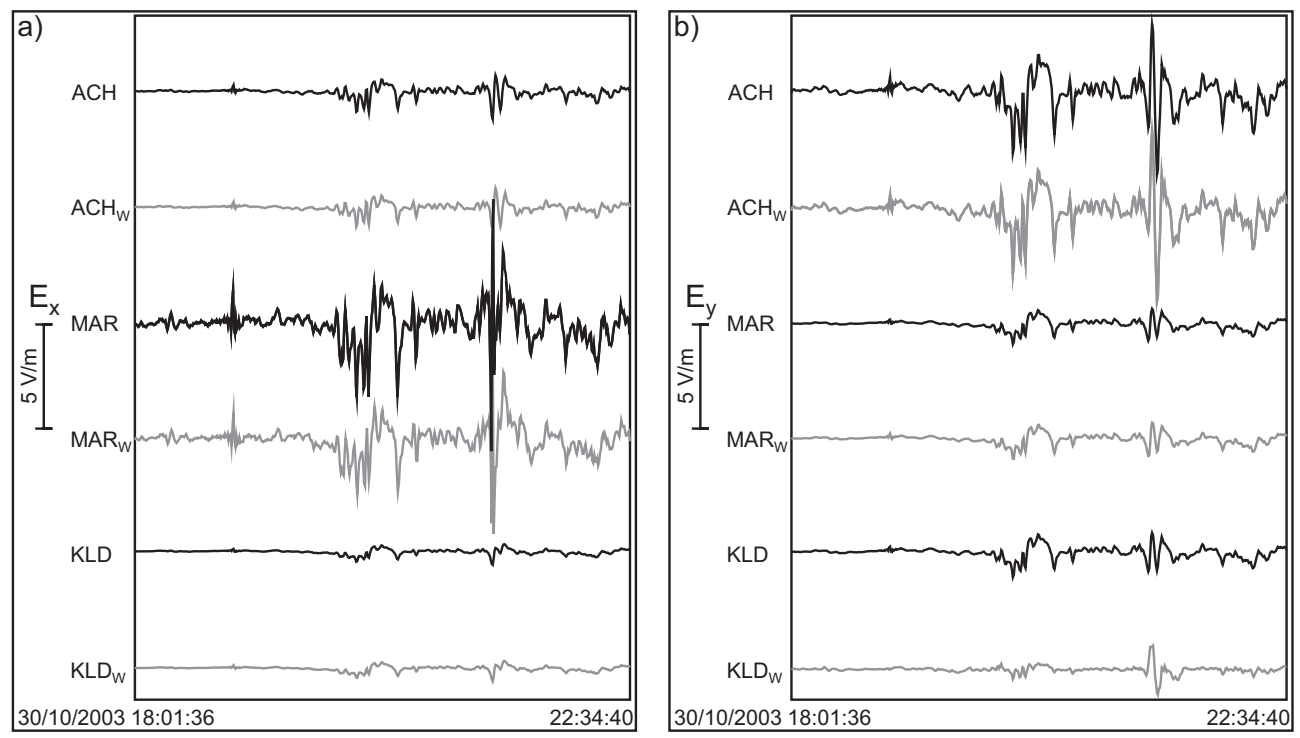

Fig. 6. Estimated (a) north-south polarised electric field $\left(E_{x}\right)$ time series; (b) east-west polarised electric field $\left(E_{y}\right)$ time series decimated to a sample rate of $32 \mathrm{~s}$ for 3 sites in Scotland during the Halloween 2003 magnetic storm obtained through frequency-domain multiplication of sitedependent impedance tensors with magnetic time series from ESK observatory. Subscript " $W$ " denotes use of impedances modified to take into account horizontal magnetic field gradients embodied in the perturbation tensor. Other time-series traces are for measured impedances. Peak electric field fluctuations occur at the same time for both $E_{x}$ and $E_{y}$ polarisations.

individual measurement sites can also be displayed in vector form (Fig. 8). This allows variations in electric field directions as well as magnitudes to be considered. From Figure 8, we see that the magnetic perturbation tensor mostly has minimal effect on the direction of these fields. A notable exception is at site CAL, where application of the perturbation-tensor correction also produces a significant diminution of the estimated electric field magnitude. As we have considered electric field magnitudes, there is a $90^{\circ}$ ambiguity in the direction of the electric field vectors displayed. However, it is clear that the directions of these vectors are not controlled solely by the directions of the coastlines. We, rather, infer a controlling influence of Earth's internal conductivity structure.

\subsection{Maximum electric field magnitudes during September 2017 storm}

Electric fields estimated from the September 2017 storm (Fig. 9) are smaller in magnitude than those estimated from the Halloween 2003 storm. However, comparing Figures 7a and $9 \mathrm{a}$, and $7 \mathrm{~b}$ and $9 \mathrm{~b}$, both sets of electric fields exhibit broadly similar regional patterns. Anomalously large $E_{x}$ fields were measured (Simpson \& Bahr, 2020b) at site ACH during the September 2017 storm compared to those estimated (Simpson \& Bahr, 2020a). We attribute this discrepancy to possible current-channelling effects from a nearby railway line. More measurements would be required to delineate this effect better. North-south polarised electric fields at the other sites for which storm-time data are available agree better and there is good agreement between estimated and measured $E_{y}$ fields at all 7 sites where data are available. As for the Halloween 2003 magnetic storm, maximum peak-to-peak electric field variations coincide temporally for the $E_{x}$ and $E_{y}$ polarisations. Vector electric fields are shown in Figure 10.

\subsection{Transmission-line voltages}

\subsubsection{Halloween 2003 storm}

The hazard maps shown in Figure 7 have been used to estimate the average magnitudes of the maximum peak-to-peak electric fields along the 12 high-voltage transmission lines shown in Figure 1 during the Halloween 2003 magnetic storm. Electric fields estimated from both $\boldsymbol{Z}_{i j}$ and $\boldsymbol{Z}_{i j}^{\prime}$ are tabulated in Table 1. Transmission-line voltages associated with these electric fields are also shown in Table 1. Electric fields exceed $5 \mathrm{~V} / \mathrm{km}$ along Lines 1, 4, 5 and 9. Maximum electric fields of $7.2 \mathrm{~V} / \mathrm{km}$ and $5.6 \mathrm{~V} / \mathrm{km}$ for $\boldsymbol{Z}_{i j}$ and $\boldsymbol{Z}_{i j}^{\prime}$, respectively, occur along Line 4 . However, the largest voltages occur along Line 5 due to its longer length. The largest differences between the electric fields estimated from $\boldsymbol{Z}_{i j}$ and $\boldsymbol{Z}_{i j}^{\prime}$ are along Lines 7 and 8 . Line 7 runs approximately north-south and comparing $E_{x}$ fields in Figures $7 \mathrm{a}$ and $7 \mathrm{c}$, significant differences are apparent. This line is close to the city of Glasgow, making data acquisition at additional sites difficult. Significant differences are also apparent along Line 4. However, this line is outside of our MT array and so differences may result from interpolation. The relative differences in electric field magnitudes between lines are greater than the relative differences between electric field magnitudes estimated using $\boldsymbol{Z}_{i j}$ or $\boldsymbol{Z}_{i j}^{\prime}$ for individual lines. However, magnetic perturbations across the region are relatively low (Fig. 2) and we recommend testing the technique in a region with more pronounced horizontal magnetic gradients.

\subsubsection{September 2017 storm}

The hazard maps shown in Figure 9, computed using measured storm-time magnetic fields (Simpson \& Bahr, 2020a, 2020b) from RAN (Fig. 1) have been used to estimate the 




Fig. 7. Bicubic-spline interpolated (Smith \& Wessel, 1990), maximum peak-to-peak, Halloween storm-time, electric field magnitudes at $21: 20$ UT on 30th October 2003 for (a) $E_{x}$ and (b) $E_{y}$ polarisation using measured impedances $\left(\boldsymbol{Z}_{i j}\right)$; c) $E_{x}$ and d) $E_{y}$ polarisation using modified impedances $\left(\boldsymbol{Z}_{i j}^{\prime}\right)$. Stars indicate impedance-tensor site locations.

average magnitudes of the maximum peak-to-peak electric fields along the 12 high-voltage transmission lines shown in Figure 1 during the September 2017 magnetic storm. In Table 2, we compare line-averaged electric fields and transmission-line voltages estimated from $\boldsymbol{Z}_{i j}$ and the measured storm-time magnetic fields at RAN (Simpson \& Bahr, 2020b) with those that result when measured electric fields $\left(\boldsymbol{E}_{\text {meas }}\right)$ from sites $\mathrm{ACH}$, ELC, CAI, TAN, MAR, LEA and RAN (Simpson \& Bahr, 2020a, 2020b) are substituted for the estimated electric fields at those sites. This substitution has the largest effect for Lines 4, 5 and 2, which are closest to sites MAR, TAN, ELC and CAI (Fig. 1). Electric fields only reach approximately $1 \mathrm{~V} / \mathrm{km}$ along Lines 4 and 9. As with the Halloween 2003 storm, the largest voltages occur along Line 5 due to its longer length. Site $\mathrm{ACH}$ is sufficiently far from north-south oriented, long-distance, high-voltage power transmission lines that the anomalously large $E_{x}$ fields measured here do not influence transmission-line voltages. However, these anomalous fields serve to illustrate the 


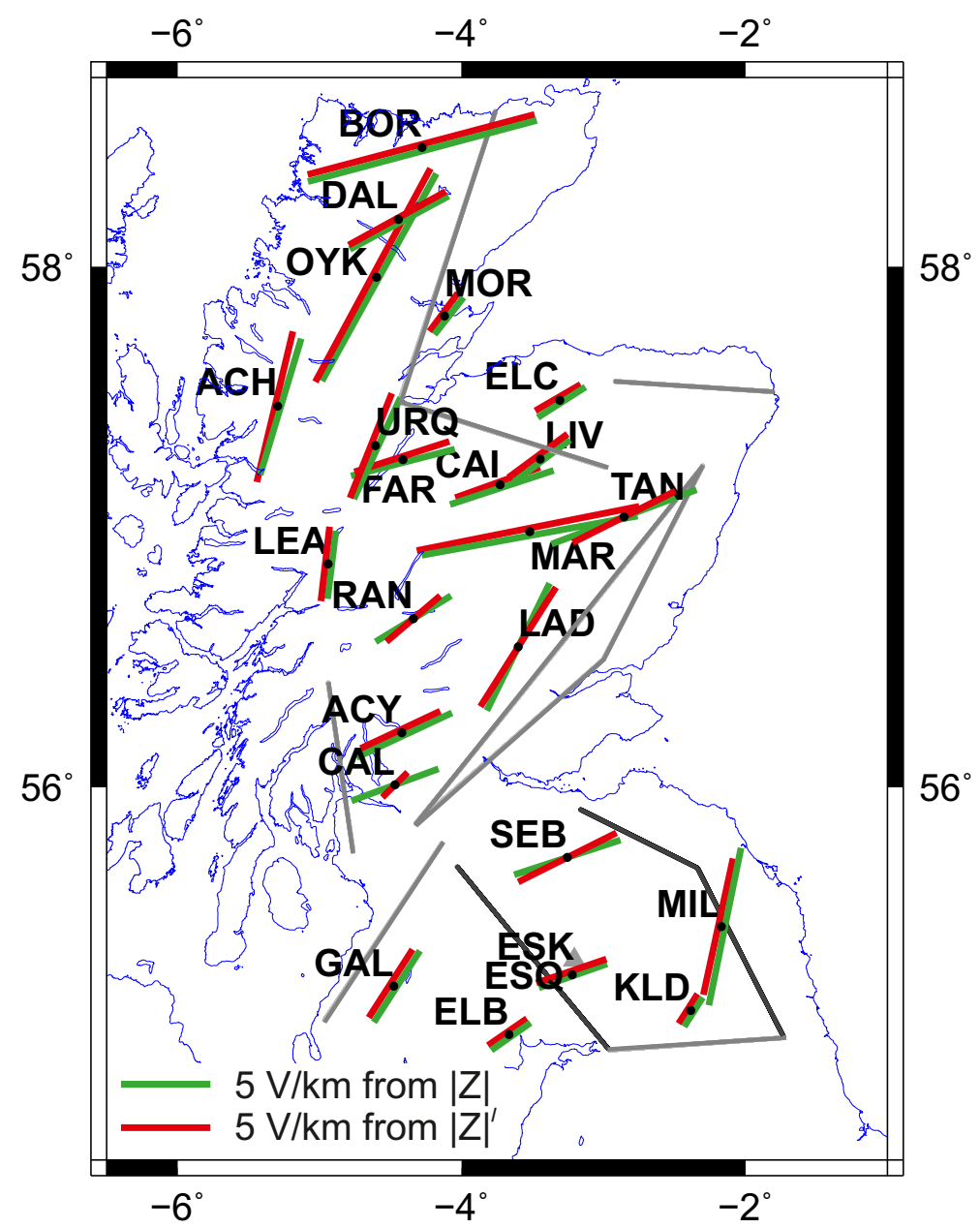

Fig. 8. Vector representation of the maximum peak-to-peak, Halloween storm-time, electric field magnitudes at 21:20 UT on 30th October 2003. There is an inherent $90^{\circ}$ ambiguity in these directions. However, they mostly do not correspond with the directions of coastlines outlined in blue. Light and dark grey lines are the longest $(>50 \mathrm{~km}) 12$ high-voltage $-275 \mathrm{kV}$ and $400 \mathrm{kV}$, respectively - transmission lines in the region (Viljanen et al., 2013).

necessity of improving our monitoring of local electric fields for space weather applications.

\subsection{Comparison of Halloween 2003 and September 2017 storms}

In Figure 11, we compare the magnitudes and directions of the electric fields estimated at the times of peak magnetic field strength during the Halloween (Fig. 8) and September 2017 storms (Fig. 10). For the Halloween 2003 storm, magnetic fields from ESK geomagnetic observatory were multiplied with $\boldsymbol{Z}_{i j}$. However, due to gaps in the magnetic time series received from ESK for September 2017, we have multiplied magnetic field spectra from site RAN (Fig. 1) with $\boldsymbol{Z}_{i j}$ to estimate electric fields for the September 2017 storm. At the majority of sites, maximum peak-to-peak electric fields are estimated to be approximately 5 times larger for the event that occurred on 30th October 2003 during the Halloween 2003 storm compared to that which occurred on 8th September 2017. Notwithstanding the use of different magnetic field sites, the electric field vectors at a 1:5 scaling ratio for the two storms are similar in direction and magnitude at most sites (Fig. 11). For most sites, differences arising from storm-time magnetic fields from ESK and RAN are significantly smaller than the differences between vectors at neighbouring sites. These differences are governed by differences in subsurface conductivity structure as characterised by the impedance tensor. This suggests that hazard maps derived from poorly-constrained impedances - e.g., ones synthesised from overly-simplified conductance models that account for only near-surface contrasts such as ocean bathymetry - are likely to be unreliable. At sites ACY and CAL significant differences in both magnitude and direction are evident in the electric field vectors for the two storms. As the same magnetic fields have been used at all sites and other sites show more similarity for the two storms, we attribute this observation to coupling between different frequencies present in the magnetic field spectra for the two storms with anomalous subsurface conductivities in this region. This demonstrates a possible weakness in upscaling magnetic storm intensities from indices such as Dst and $\mathrm{Kp}$ that do not take into account spectral content to predict magnitudes of 100-year storms (e.g., Lucas et al., 2020). 


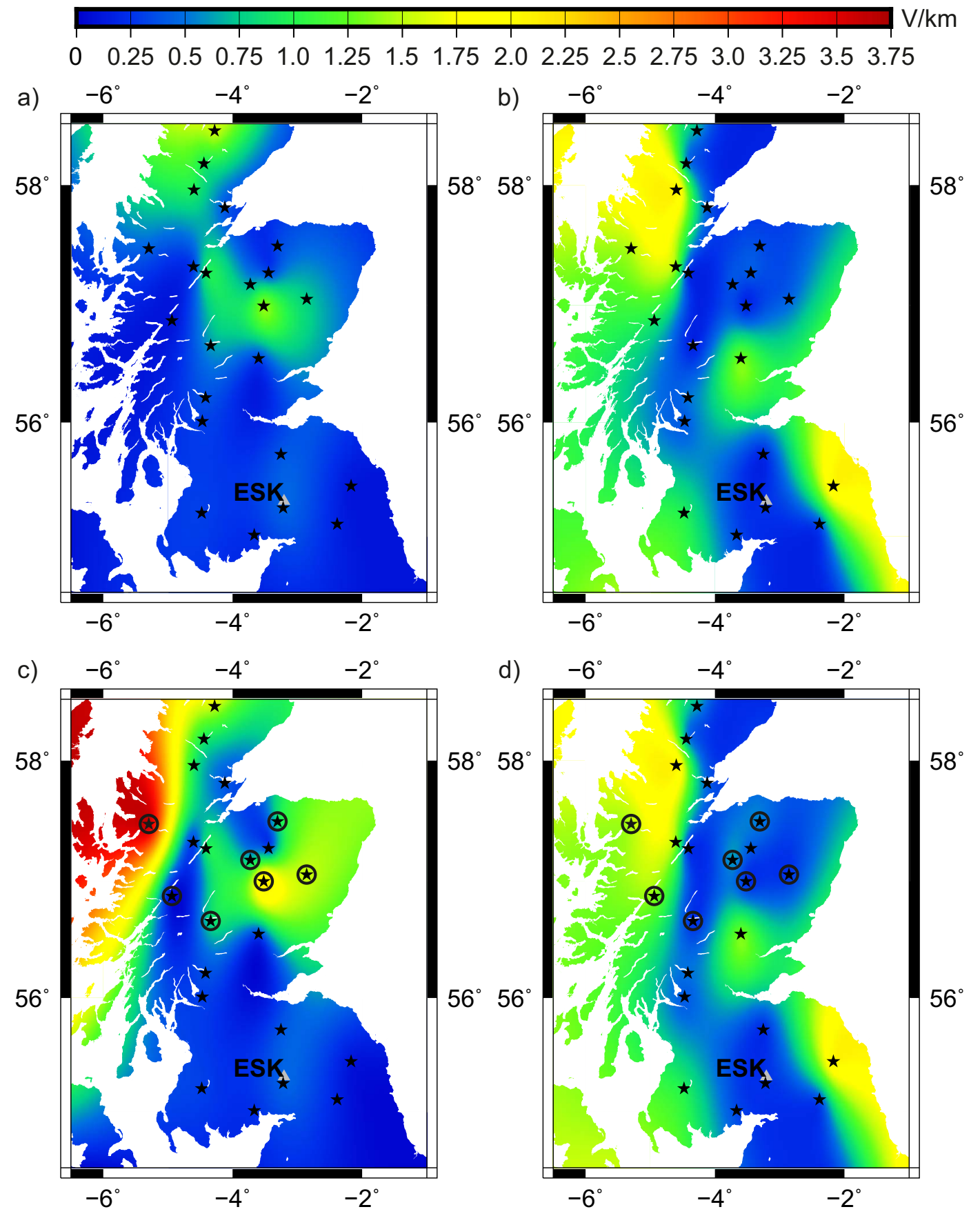

Fig. 9. Bicubic-spline interpolated (Smith \& Wessel, 1990) maximum peak-to-peak electric-field magnitudes at UT 01:25 during the 8th September 2017 magnetic storm for (a) $E_{x}$ and (b) $E_{y}$ polarisation using measured impedances $\left(\boldsymbol{Z}_{i j}\right)$ and measured magnetic fields from RAN (Fig. 1); (c) $E_{x}$ and (d) $E_{y}$ polarisation with estimated electric fields replaced with measured storm-time electric fields (Simpson \& Bahr, 2020b) at sites ACH, ELC, CAI, TAN, MAR, LEA and RAN (Fig. 1). Black stars indicate impedance-tensor site locations, circled stars in panel (c) and (d) indicate sites at which measured electric fields have been substituted for the estimated fields used in panels (a) and (b).

\section{Discussion and Conclusion}

We have used MT impedances and geomagnetic perturbation tensors from Scotland and northern England for estimating electric fields associated with the Halloween 2003 magnetic storm for which only regional magnetic time series from ESK observatory are otherwise available. Our analysis shows the possibility of mitigating the risks of magnetic storms on power-grid transformers by running future, long-distance power lines associated with green energy initiatives preferentially along a corridor for which peak-to-peak electric field magnitudes (Fig. 7) during the Halloween 2003 storm were low. On the other hand, at sites MAR (Fig. 1; in the Cairngorms area of Scotland) and BOR (Fig. 1; in the northern Highlands) 


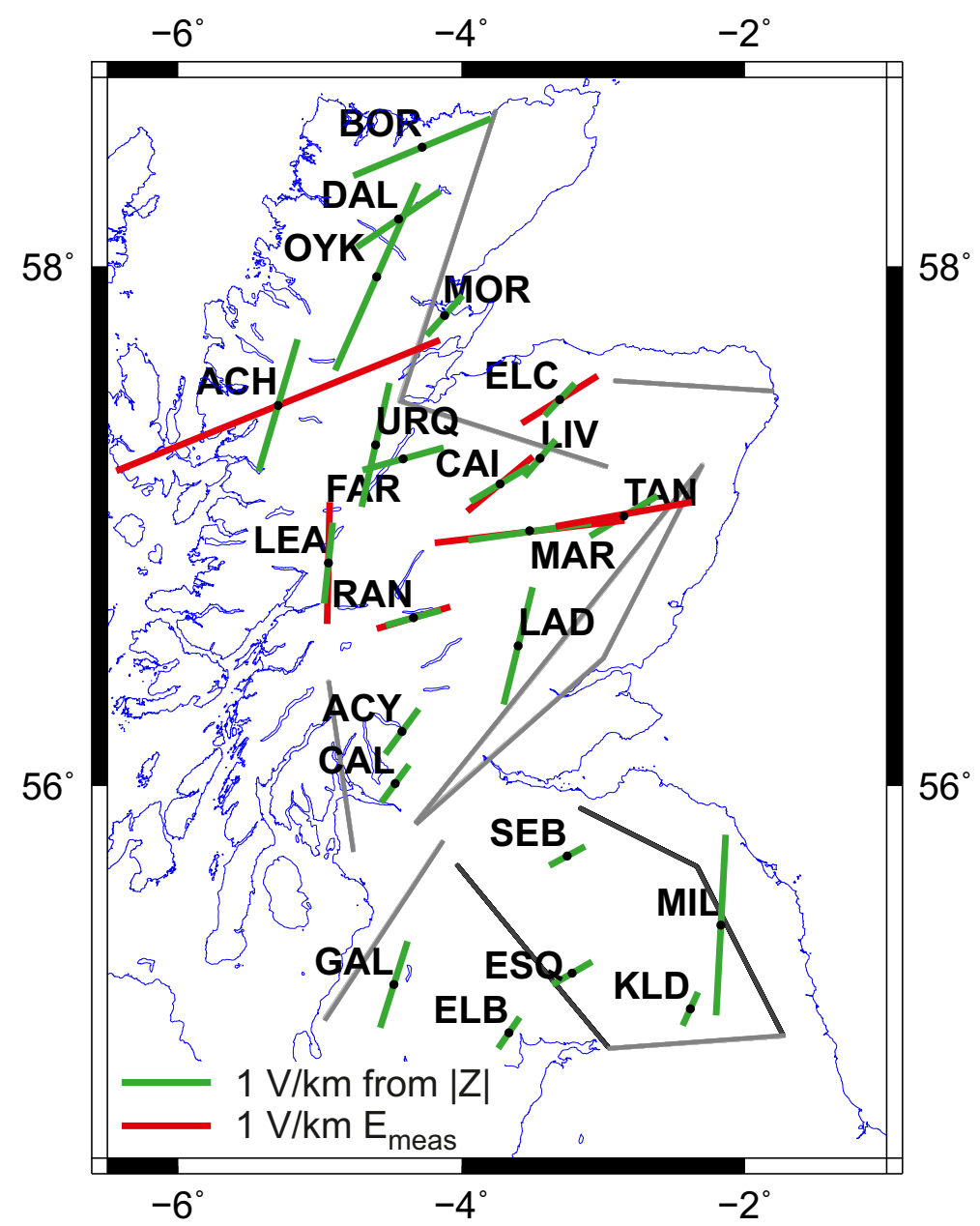

Fig. 10. Vector representation of the maximum peak-to-peak, September 2017 storm-time, electric field magnitudes at $01: 25$ UT on 8 th September 2017. There is an inherent $90^{\circ}$ ambiguity in these directions. However, they mostly do not correspond with the directions of coastlines. Light and dark grey lines are the longest $(>50 \mathrm{~km}) 12$ high-voltage $-275 \mathrm{kV}$ and $400 \mathrm{kV}$, respectively - transmission lines in the region (Viljanen et al., 2013).

Table 1. Maximum peak-to-peak electric fields for the Halloween 2003 magnetic storm averaged (see Methods Sect. 2.2) in directions delineated by the 12 high-voltage (HV) transmission lines shown in Figure 1 and their associated transmission-line voltages. $\boldsymbol{E}^{\prime} / \boldsymbol{E}$ percentages are the magnitudes of quantities estimated using $\boldsymbol{Z}_{i j}^{\prime}$ relative to those estimated using $\boldsymbol{Z}_{i j}$.

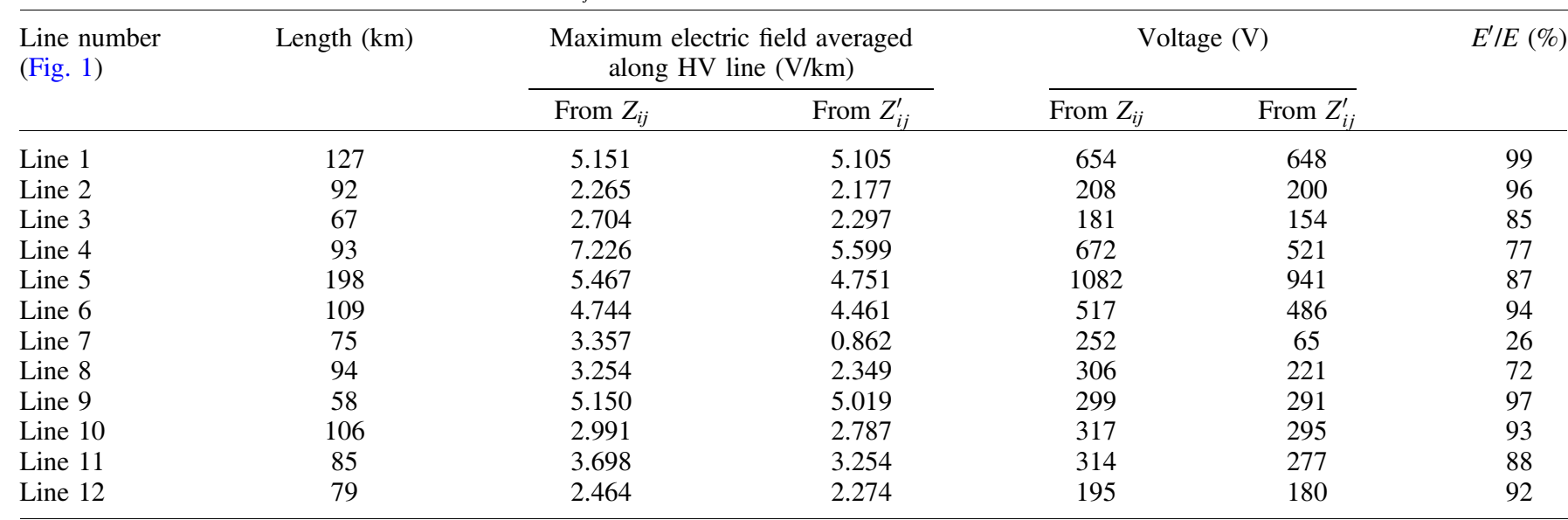


Table 2. Maximum peak-to-peak electric fields for the September 2017 magnetic storm averaged (see Methods Sect. 2.2) in directions delineated by the 12 high-voltage (HV) transmission lines shown in Figure 1 and their associated transmission-line voltages. $\boldsymbol{E}_{\text {meas }}$ are the measured electric fields (Simpson \& Bahr, 2020a, 2020b) from sites ACH, ELC, CAI, TAN, MAR, LEA and RAN. $\boldsymbol{E}_{\text {meas }} / \boldsymbol{E}$ percentages are the magnitudes of quantities estimated with $\boldsymbol{E}_{\text {meas }}$ substituted from the aforementioned 7 sites relative to those estimated using $Z_{i j}$.

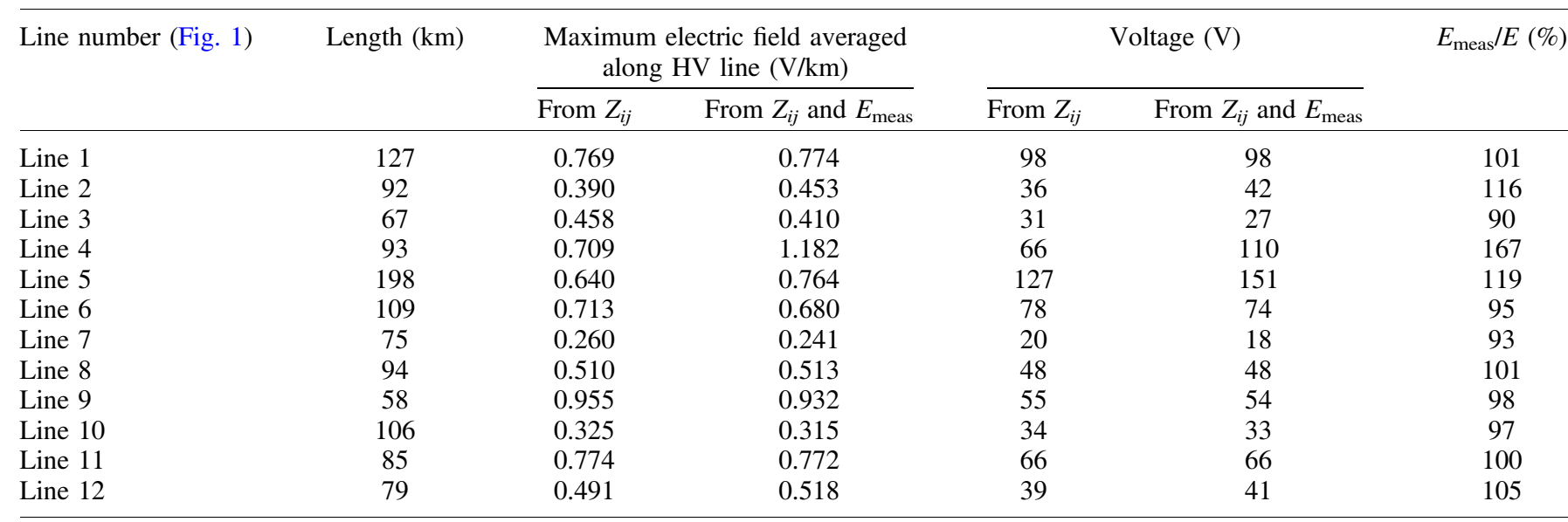

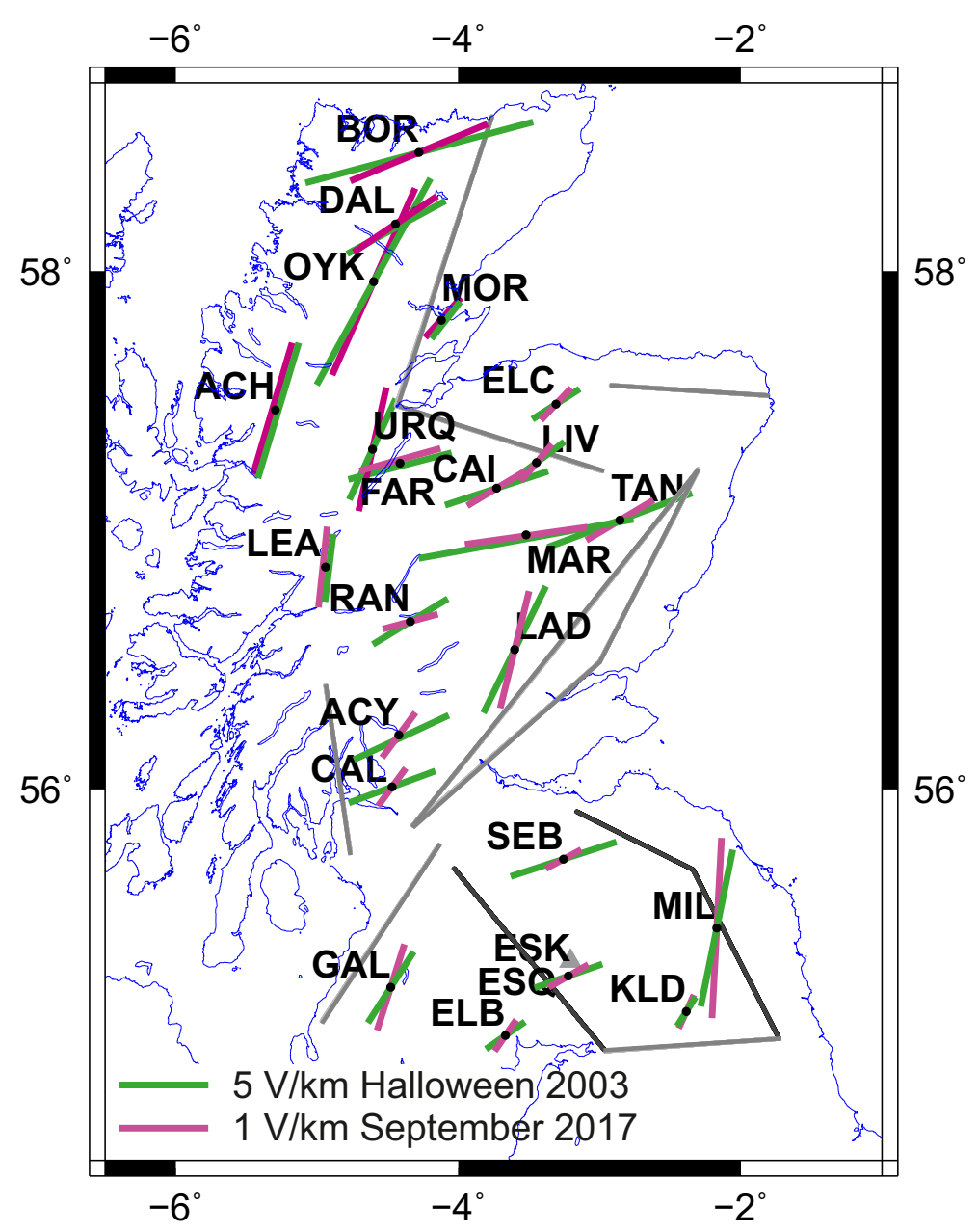

Fig. 11. Comparison of maximum peak-to-peak, storm-time, electric field magnitudes and directions estimated for the Halloween storm at 21:20 UT on 30th October 2003 and September 2017 storm at 01:25 UT on 8th September 2017. In both cases, electric fields were estimated by multiplying storm-time, magnetic fields with $\boldsymbol{Z}_{i j}$ from the individual site. For the Halloween 2003 storm, magnetic fields from ESK were used, whereas for the September 2017 storm, magnetic fields from RAN were used. Note 1:5 scaling of the lengths of the vectors for the two storms. 
maximum peak-to-peak electric field amplitudes may have reached $13 \mathrm{~V} / \mathrm{km}$ and these are identified as high-risk regions. 3D electrical conductivity modelling is being undertaken to understand the underlying causes of these electric field variations. However, an advantage of the method of estimating electric fields from impedance tensors and magnetic fields is that it can provide storm-time electric field estimates more quickly than 3D modelling techniques. We note that decisions related to the construction of power-line networks cannot be dictated purely by space weather considerations. However, the mountainous topography of the high-risk Cairngorms region (e.g. site MAR; Fig. 1) also makes it a more difficult environment through which to pass long-distance power lines. In addition to electric-power companies, our electric field hazard maps will be of use to gas-pipeline and railway-signal operators.

Although horizontal magnetic gradients across Scotland and northern England are small, they affect the maximum peak-topeak electric field magnitudes responsible for driving GICs along Lines 4, 7 and 8. For the case of the Halloween 2003 magnetic storm, the effect is most pronounced for Line 7, where a factor of 3.9 difference occurs between electric fields computed with and without the perturbation-tensor correction; along Lines 4 and 8, this factor is 1.3-1.4 (Table 1). However, with the exception of Line 7 , the effects of the perturbation-tensor correction are small (15\% or less) compared to the differences between lines running along different trajectories across different regions with varying 3D, subsurface, electrical conductivity structures (Table 1).

We find that electric field amplitudes during the Halloween magnetic storm may have exceeded the $2 \mathrm{~V} / \mathrm{km}$ (Boteler, 1994) inferred to have caused power outages in Québec, Canada as a result of the March 1989 geomagnetic storm along all long-distance, high-voltage transmission lines; electric field fluctuations averaged over Lines 1, 4 and 9 exceed $5 \mathrm{~V} / \mathrm{km}$. This indicates that areas of Scotland could be vulnerable to extreme space weather events. However, we note that the existing and future level of vulnerability to such events will be dependent on mitigation procedures and transformer specifications.

For the September 2017 storm, peak-to-peak electric fields in the environs of the long-distance, high-voltage transmission lines considered were of the order $1 \mathrm{~V} / \mathrm{km}$, or less. Transmission-line voltages of between 20 and $150 \mathrm{~V}$ are estimated compared to transmission-line voltages of 150-1000 V for the Halloween storm. As for the Halloween storm, the largest voltages are estimated along Line 5.

Direct comparison of the electric field vectors obtained for the Halloween 2003 and September 2017 storms (Fig. 11) emphasises the importance of the spectral content of the storm-time magnetic field spectra and its coupling with Earth's $3 \mathrm{D}$ conductivity structure. This indicates that inadequate knowledge of magnetic source field characteristics and/or Earth's deep electrical conductivity structure could lead to unreliable space weather forecasts.

The regional and direction-dependent variability of the line-average electric fields and transmission-line voltages demonstrated in this study results from Earth's 3D, electrical conductivity structure, which is embodied in the MT impedances and perturbation tensors. Surface geology and ocean bathymetry are inadequate to constrain subsurface electrical conductivities. Therefore, a programme of MT data acquisition in the UK similar to Earthscope in the US (e.g., Schultz, 2009;
Yang et al., 2015), BEAR in Sweden (Bahr \& Simpson, 2002; Korja et al., 2002) and SWEMDI in Ireland (Campanyà et al., 2019) that will enable the Earth's heterogeneous conductivity structure to be properly characterised is seen to be a prerequisite for any UK-wide space weather nowcasting and forecasting capability. Application of the perturbation-tensor correction technique to other regions with larger horizontal magnetic field gradients is also recommended.

Acknowledgements. This work was supported by the Natural Environment Research Council (NERC Grant NE/ P016782/1). We thank Forestry Commission Scotland, National Trust for Scotland and Glen Tanar Estate for allowing us to install MT instrumentation on their land. MT data collected by the authors will be made available through the National Geoscience Data Centre (NGDC), UK by the end of the project (December 2021). The results presented in this paper also rely on geomagnetic data collected at ESK geomagnetic observatory at the end of October 2003. We thank the British Geological Survey (BGS) for supporting its operation and INTERMAGNET for promoting high standards of magnetic observatory practice. Maps were generated using the Generic Mapping Tool, GMT (Wessel et al., 2013). We also thank Benjamin Murphy and an anonymous reviewer for thoughtful reviews that helped us to improve an earlier version of our manuscript. The editor thanks Ari Viljanen and Benjamin Murphy for their assistance in evaluating this paper.

\section{References}

Bahr K, Olsen N, Shankland TJ. 1993. On the combination of the magnetotelluric and the geomagnetic depth sounding method for resolving an electrical conductivity increase at $400 \mathrm{~km}$ depth. Geophys Res Lett 20(2937-2940): 1993. https://doi.org/10.1029/ 93GL02134.

Bahr K, Simpson F. 2002. Electrical anisotropy below slow- and fast-moving plates: Palaeoflow in the upper mantle? Science 295: 1270-1272. https://doi.org/10.1126/science.1066161.

Beamish D, Clark TDG, Clarke E, Thomson AWP. 2002. Geomagnetically induced currents in the UK: Geomagnetic variations and surface electric fields. J Atmos Sol-Terr Phys 64: 1779-1792. https://doi.org/10.1016/S1364-6826(02)00127-X.

Beggan C, Beamish D, Richards A, Kelly G, Thomson AWP. 2013. Prediction of extreme geomagnetically induced currents in the UK high-voltage network. Space Weather 11: 407-419. https://doi.org/ 10.1002/swe20065.

Bigalke J, Grabner EW. 1997. The Geobattery model: a contribution to large scale electrochemistry. Electrochim Acta 42: 3443-3452. https://doi.org/10.1016/S0013-4686(97)00053-4.

Bolduc L. 2002. GIC observations and studies in the Hydro-Québec power system. J Atmos Sol-Terr Phys 64: 1793-1802. https://doi. org/10.1016/S1364-6826(02)00128-1.

Boteler DH. 1994. Geomagnetically induced currents: Present knowledge and future research. IEEE Trans Power Deliv 9: 50-58.

Boteler DH. 2003. Geomagnetic hazards to conducting networks. Nat Haz 28: 537-561. https://doi.org/10.1023/A:1022902713136.

Campanyà J, Gallagher PT, Blake SP, Gibbs M, Jackson D, Beggan CD, Richardson GS, Hogg C. 2019. Modeling geoelectric fields in Ireland and the UK for space weather applications. Space Weather 17: 216-237. https://doi.org/10.1029/2018SW001999. 
Cannon P, Angling M, Barclay L, Curry C, Dyer C, et al. 2013. Extreme space weather impacts on engineered systems and infrastructure. UK Royal Academy of Engineering, London, pp. 69. ISBN: 1-903496-95-0.

Carrington RC. 1860. Description of a singular appearance seen in the Sun on September 1, 1859. Mon Not R Astron Soc 20: 13-15. https://doi.org/10.1093/mnras/20.1.13.

Chapman S, Ferraro V. 1931. A new theory of magnetic storms. Terr Mag 36: 77-97. https://doi.org/10.1029/TE036i003p00171.

Cliver EW, Svalgaard L. 2004. The 1859 solar-terrestrial disturbance and the current limits of extreme space weather activity. Sol Phys 224: 407-422. https://doi.org/10.1007/s11207-005-4980-z.

Egbert GD, Booker JR. 1986. Robust estimation of geomagnetic transfer functions. Geophys $J$ R Astron Soc 87: 173-194. https://doi.org/10.1111/j.1365-246X.1986.tb04552.x.

Filloux J.H. 1987. Instrumentation and experimental methods for oceanic studies. In: Geomagnetism, Volume 1, Jacobs J.A. (Ed.), Academic Press, London, pp. 143-248. ISBN: 9780123786715.

Gummow RA, Eng P. 2002. GIC effects on pipeline corrosion and corrosion control systems. J Atmos Sol-Terr Phys 64: 1755-1764. https://doi.org/10.1016/S1364-6826(02).00125-6.

Haak V, Hutton VRS. 1986. Electrical resistivity in continental lower crust. In: The nature of the lower continental crust, Dawson J.B., Carswell D.A., Hall J., Wedepohl K.H. (Eds.), Geol. Soc. Special Publication, 24, Blackwell Scientific Publications, Oxford, pp. 35-49. ISBN: 0632015616.

Haak V, Simpson F, Bahr K, Bigalke J, Eisel M, et al. 1997. KTB and the electrical conductivity of the crust. $J$ Geophys Res 102: 18289-18305. https://doi.org/10.1029/96JB03861.

Hanekop O, Simpson F. 2006. Error propagation in electromagnetic transfer functions: What role for the magnetotelluric method in detecting earthquake precursors? Geophys J Int 165: 763-774. https://doi.org/10.1111/j.1365-246X.2006.02948.x.

Hodgson R. 1859. On a curious appearance seen in the Sun. Mon Not $R$ Astron Soc 20: 15-16. https://doi.org/10.1093/mnras/20.1.15.

Hutton VRS, Sik JM, Gough DI. 1977. Electrical conductivity and tectonics of Scotland. Nature 266: 617-620. https://doi.org/ $10.1038 / 266617 \mathrm{a} 0$.

Ivannikova E, Kruglyakov M, Kuvshinov A, Rastätter L, Pulkkinen AA. 2018. Regional 3-D modeling of ground electromagnetic field due to realistic geomagnetic disturbances. Space Weather 16: 476-500. https://doi.org/10.1002/2017SW001793.

Kelbert A. 2019. The role of global/regional earth conductivity models in natural geomagnetic hazard mitigation. Surv Geophys 41(1): 115-166. https://doi.org/10.1007/s10712-019-09579-z.

Kelbert A, Balch CC, Pulkkinen A, Egbert GD, Love JJ, Rigler EJ, Fujii I. 2017. Methodology for time-domain estimation of storm time geoelectric fields using the 3-D magnetotelluric response tensors. Space Weather 15: 874-894. https://doi.org/10.1002/ 2017 SW001594.

Kelly GS, Viljanen A, Beggan CD, Thomson AWP. 2017. Understanding GIC in the UK and French high-voltage transmission systems during severe magnetic storms. Space Weather 15: 99-114. https://doi.org/10.1002/2016SW001469.

Kennedy WQ. 1946. The Great Glen Fault. Quart J Geol Soc Lond 102: 41-76. https://doi.org/10.1144/GSL.JGS.1946.102.01-04.04.

Korja T, Engels M, Zhamaletdinov AA, Kovtun AA, Palshin NA, Smirnov MY, Tokarev AD, Asming VE, Vanyan LL, Vardaniants IL, the BEAR Working Group. 2002. Crustal conductivity in Fennoscandia - A compilation of a database on crustal conductance in the Fennoscandian Shield. Earth Planets Space 54: 535558. https://doi.org/10.1186/BF03353044.
Krausmann E, Andersson E, Russel T, Murtagh W. 2015. Space weather and rail: Findings and outlook. EU Joint Research Centre report, Publications Office of the EU, Luxembourg, 29 p. https://doi.org/10.2788/211456.

Kurtz RD, Craven JA, Niblett ER, Stevens RA. 1993. The conductivity of the crust and mantle beneath the Kapuskasing uplift: Electrical anisotropy in the upper mantle. Geophys J Int 113: 483 498. https://doi.org/10.1111/j.1365-246X.1993.tb00901.x.

Lucas GM, Love JJ, Kelbert A. 2018. Calculation of voltages in electric power transmission lines during historic geomagnetic storms: An investigation using realistic earth impedances. Space Weather 16: 185-195. https://doi.org/10.1002/ 2017SW001779.

Lucas G, Love JJ, Kelbert A, Bedrosian PA, Rigler EJ. 2020. A 100year geoelectric hazard analysis for the U.S. high-voltage power grid. Space Weather 18: e2019SW002329. https://doi.org/ 10.1029/2019SW002329.

OECD. 2018. National risk assessments: A cross country perspective, OECD Publishing, Paris. https://doi.org/10.1787/ 9789264287532-en.

Oliver GJH, Stone P, Bluck BJ. 2002. The Ballantrae Complex and Southern Uplands terrane. In: The Geology of Scotland, The Geological Society, London, Trewan NH (Ed.), pp. 167-200. https://doi.org/10.1144/GOS4P.6.

Pulkkinen A, Lindahl S, Viljanen A, Pirjola R. 2005. Geomagnetic storm of 29-31 October 2003: Geomagnetically induced currents and their relation to problems in the Swedish high-voltage power transmission system. Space Weather 3: S08C03. https://doi.org/ 10.1029/2004SW00123.

Pulkkinen A, Viljanen A, Pirjola R. 2006. Estimation of geomagnetically induced current levels from different input data. Space Weather 4: S08005. https://doi.org/10.1029/2006SW000229.

Schmucker U. 1973. Regional induction studies: A review of methods and results. Phys Earth Planet Int 7: 365-378. https://doi. org/10.1016/0031-9201(73)90061-7.

Schultz A. 2009. EMSCOPE: A continental scale magnetotelluric observatory and data discovery resource. Data Sci J 8: PIGY6PIGY20. https://doi.org/10.2481/dsj.SS_IGY-009.

Simpson F. 1999. Stress and seismicity in the lower continental crust: A challenge to simple ductility and implications for electrical conductivity mechanisms. Surv Geophys 20: 201-227. https://doi. org/10.1023/A:1006641922180.

Simpson F. 2000. A three-dimensional electromagnetic model of the southern Kenya Rift: Departure from two-dimensionality as a possible consequence of a rotating stress field. J Geophys Res 105: 19321-19334. https://doi.org/10.1029/2000JB900106.

Simpson F. 2001. Resistance to mantle flow inferred from the electromagnetic strike of the Australian upper mantle. Nature 412: 632-635. https://doi.org/10.1038/35088051.

Simpson F. 2002. A comparison of electromagnetic distortion and resolution of upper mantle conductivities beneath continental Europe and the Mediterranean using islands as windows. Phys Earth Planet Int 129: 117-130. https://doi.org/10.1016/S00319201(01)00264-3.

Simpson F, Bahr K. 2005. Practical magnetotellurics, Cambridge University Press, London, 254 p. ISBN: 9781108462556. https://doi.org/10.1017/CBO9780511614095.

Simpson F, Bahr K. 2020a. Nowcasting and validating Earth's electric field response to extreme space weather events: Application to the September 2017 geomagnetic storm and comparison to observed and modelled fields in Scotland. Space Weather 18: e2019SW002432. https://doi.org/10.1029/2019SW002432. 
Simpson F, Bahr K. 2020b. Magnetotelluric data from before, during and after the September 2017 magnetic storm at 7 sites in Scotland, National Geoscience Data Centre, British Geological Survey, Keyworth, UK (Dataset). https://doi.org/10.5285/ 59d3c54d-8179-4904-8ee7-1a81564ed893.

Simpson F, Warner M. 1998. Coincident magnetotelluric, P-wave and S-wave images of the deep continental crust beneath the Weardale granite, NE England: Seismic layering, low conductance and implications against the fluids paradigm. Geophys $J$ Int 133: 419-434. https://doi.org/10.1046/j.1365-246X.1998.00512.x.

Siripunvaraporn W, Egbert G, Lenbury Y, Uyeshima M. 2005. Three-dimensional magnetotelluric: Data space method. Phys Earth Planet Int 150: 3-14. https://doi.org/10.1016/j.pepi.2004. 08.023.

Smith WHF, Wessel P. 1990. Gridding with continuous curvature splines in tension. Geophysics 55: 293-305. https://doi.org/ 10.1190/1.1442837.

Stevenson RL. 1886. Strange case of Dr Jekyll and Mr Hyde. Longmans, Green \& Co, London. ISBN: 978-0-553-21277-8.

Tanner G. 2008. Tectonic significance of the Highland Boundary Fault, Scotland. J Geol Soc 165: 915-921. https://doi.org/10.1144/ 0016-76492008-012.
Thomson AWP, McKay AJ, Clarke E, Reay SJ. 2005. Surface electric fields and geomagnetically induced currents in the Scottish Power grid during the 30 October 2003 geomagnetic storm. Space Weather 3: S11002. https://doi.org/10.1029/2005SW000156.

Tsurutani BT, Gonzalez WD, Lakhina GS, Alex S. 2003. The extreme magnetic storm of 1-2 September 1859. J Geophys Res 108: 1268. https://doi.org/10.1029/2002JA009504.

Viljanen A, Pulkkinen A, Pirjola R, Pajunpää K, Posio P, Koistinen A. 2006. Recordings of geomagnetically induced currents and a nowcasting service of the Finnish natural gas pipeline system. Space Weather 4: S10004. https://doi.org/10.1029/2006SW000234.

Viljanen A, Pirjola R, Ádám A, Prácser E, Sakharov Y, Katkalov J. 2013. Continental scale modelling of geomagnetically induced currents. J Space Weather Space Clim 2: A17. https://doi.org/ $10.1051 /$ swsc/2012017.

Wessel P, Smith WHF, Scharroo R, Luis J, Wobbe F. 2013. Generic mapping tools: Improved version released. EOS Trans AGU 94: 409-410. https://doi.org/10.1002/2013EO450001.

Yang B, Egbert GD, Kelbert A, Meqbel NM. 2015. Threedimensional electrical resistivity of the north-central USA from EarthScope long period magnetotelluric data. Earth Planet Sci Lett 422: 87-93. https://doi.org/10.1016/j.eps1.2015.04.006.

Cite this article as: Simpson F \& Bahr K 2020. Estimating the electric field response to the Halloween 2003 and September 2017 magnetic storms across Scotland using observed geomagnetic fields, magnetotelluric impedances and perturbation tensors. J. Space Weather Space Clim. 10, 48. https://doi.org/10.1051/swsc/2020049. 